\title{
Estimativa do potencial produtivo em trigo utilizando sensor óptico ativo para adubação nitrogenada em taxa variável
}

\author{
Wheat yield potential estimation using active optical sensor for \\ site-specific nitrogen fertilization
}

\section{Christian Bredemeier $^{\mathrm{I}}$ Clever Variani ${ }^{\mathrm{I}}$ Danielle Almeida $^{\mathrm{I}}$ Alexandre Tonon Rosa ${ }^{\mathrm{I}}$}

\section{RESUMO}

A adubação nitrogenada em trigo é baseada no potencial produtivo da cultura, teor de matéria orgânica do solo e cultura antecessora. A definição do potencial produtivo é complexa, pois este varia com as condições meteorológicas de cada ano específico. O objetivo deste trabalho foi avaliar a relação entre o índice de vegetação por diferença normalizada (NDVI), medido por sensor óptico ativo e o rendimento de grãos em quatro cultivares de trigo, visando a desenvolver procedimentos para a adubação nitrogenada em cobertura em taxa variável. $O$ experimento foi realizado em campo em 2009. Foram avaliados o NDVI em diferentes estádios de desenvolvimento e o rendimento de grãos. As leituras do NDVI ao longo do ciclo ativo foram eficientes em identificar variações de produtividade do trigo. Assim, o potencial de produtividade pode ser estimado através de medições desse índice durante a ontogenia da planta. Pode-se adotar um modelo único para descrever a relação entre NDVI e potencial produtivo para as cultivares testadas neste trabalho.

Palavras-chave: Triticum aestivum, NDVI, agricultura de precisão, Greenseeker.

\section{ABSTRACT}

Nitrogen fertilization in spring wheat is based on yield potential, soil organic matter content and previous crop. Yield potential definition is difficult, since it is affected by weather conditions. The objective of this research was to evaluate the relationship between normalized difference vegetation index (NDVI) measured by an active sensor and grain yield of four wheat cultivars. The experiment was carried out at field conditions in 2009. NDVI in different growth stages and grain yield were evaluated. NDVI measured was efficient to detect growth variability generated by $N$ availability and correlated well with grain yield for all cultivars tested, indicating that yield potential can be estimated by NDVI evaluations during crop ontogeny. One single model for the relationship between NDVI and yield potential can be used considering cultivars used in this research.
Key words: Triticum aestivum, NDVI, precision agriculture, Greenseeker.

\section{INTRODUÇÃO}

A adubação em cobertura com nitrogênio (N) é adotada para maximizar o potencial produtivo em trigo. A disponibilidade de $\mathrm{N}$ afeta o número de afilhos emitidos (SALA et al., 2005) e o número de espigas produzidas por área. BREDEMEIER \& MUNDSTOCK (2001) definiram o estádio de seis folhas expandidas do colmo principal como o momento ideal para aplicação de $\mathrm{N}$ em cobertura em trigo. O N aplicado nesse estádio reduz a mortalidade de afilhos e consolida maior número de espigas por área (BREDEMEIER \& MUNDSTOCK, 2001; WAMSER \& MUNDSTOCK, 2007).

A recomendação da dose de $\mathrm{N}$ a ser aplicada em trigo no RS baseia-se no teor de matéria orgânica do solo, a cultura precedente (soja ou milho) e a expectativa de rendimento (REUNIÃO..., 2011). Contudo, o uso dos dois primeiros indicadores para estimar a quantidade de $\mathrm{N}$ suprida pelo solo é pouco eficiente, uma vez que muitos fatores estão envolvidos no processo de mineralização do $\mathrm{N}$ orgânico (DRURY et al., 2003; POLETTO, 2004). Também a definição da "expectativa de rendimento" é complexa, pois o potencial produtivo varia em função das condições meteorológicas de cada ano específico e a probabilidade de a "expectativa de rendimento" não se concretizar é elevada. Com a

IDepartamento de Plantas de Lavoura, Faculdade de Agronomia, Universidade Federal do Rio Grande do Sul (UFRGS), 91501-970, Porto Alegre, RS, Brasil. E-mail: bredemeier@ufrgs.br. *Autor para correspondência. 
existência de variabilidade espacial e temporal desses indicadores em áreas agrícolas, geralmente, opta-se por aplicar maiores doses de $\mathrm{N}$ em cobertura para garantir elevados rendimentos (POLETTO, 2004), sem levar em consideração o potencial produtivo e sua variabilidade espacial na área. Em consequência, as reais necessidades da planta não são supridas em muitas situações, levando à aplicação de doses de $\mathrm{N}$ acima ou abaixo da exigida. Dessa maneira, é importante o uso de ferramentas que estimem o potencial produtivo da lavoura in situ, de maneira precisa e rápida, em tempo real, visando a aperfeiçoar a aplicação de $\mathrm{N}$ e permitir a aplicação desse nutriente em taxa variável.

Essa estimativa pode ser realizada pela caracterização da reflectância, que é a relação entre a radiação refletida pelo dossel e a radiação incidente e está associada à quantidade de biomassa, teor de clorofila nas folhas e potencial produtivo da cultura (GROHS et al., 2009). Sua medição foi adaptada para uso agrícola com o desenvolvimento de sensores proximais, tais como Greenseeker, N-Sensor e Crop Circle (FENG et al., 2008; SCHMIDT et al., 2009; ERDLE et al., 2011).

Um dos índices de reflectância mais utilizados é o índice de vegetação por diferença normalizada (NDVI - Normalized Difference Vegetation Index), dado pela relação ( $\rho$ nir-pr)/ ( $\rho$ nir $+\rho r)$, em que $\rho$ nir e $\rho r$ são as reflectâncias no infravermelho próximo e no vermelho, respectivamente (ROUSE et al., 1973). A reflectância no infravermelho próximo é uma estimativa do acúmulo de biomassa e do estádio de desenvolvimento da cultura (PEÑUELAS \& FILELLA, 1998), refletindo seu potencial produtivo (GROHS et al., 2009).

O objetivo deste trabalho foi avaliar a relação entre o NDVI em diferentes estádios do desenvolvimento e o rendimento de grãos de quatro cultivares de trigo, visando a desenvolver procedimentos mais precisos para a adubação nitrogenada em cobertura.

\section{MATERIAL E MÉTODOS}

O experimento foi conduzido em 2009 na Estação Experimental Agronômica da Universidade Federal do Rio Grande do Sul, em Eldorado do Sul (RS), em solo classificado como Argissolo vermelho distrófico típico (STRECK et al., 2008), com as seguintes características: argila $=260 \mathrm{mg} \mathrm{g}^{-1}$; $\mathrm{pH}_{\text {agua }} 5,4 ; \mathrm{P}=31 \mathrm{mg} \mathrm{dm}^{-3} ; \mathrm{K}=183 \mathrm{mg} \mathrm{dm}^{-3}$ e matéria orgânica $=16 \mathrm{mg} \mathrm{g}^{-1}$. O clima é classificado, segundo
Köppen, como Cfa (subtropical, de verão úmido e quente). A precipitação média anual é de $1445 \mathrm{~mm}$ e a temperatura média mensal varia entre $13,5^{\circ} \mathrm{C}$ (junho) e $24,6^{\circ} \mathrm{C}$ (janeiro) (BERGAMASCHI et al., 2003).

Em sucessão às culturas de milho e soja, foi instalado experimento com os seguintes tratamentos: a) quatro cultivares de trigo ('Abalone', 'Marfim', 'Quartzo' e 'Fundacep Raízes'); b) quatro níveis de $\mathrm{N}$ aplicados na emergência das plantas (sem $\mathrm{N}, 20,40$ e $60 \mathrm{~kg} \mathrm{ha}^{-1}$ de $\mathrm{N}$ ); e c) cinco níveis de $\mathrm{N}$ aplicados em cobertura (sem N, 20, 40, 60 e $80 \mathrm{~kg} \mathrm{ha}^{-1}$ de $\mathrm{N}$ ), na forma de ureia, no estádio de seis folhas completamente expandidas no colmo principal.

$\mathrm{O}$ experimento foi conduzido no delineamento experimental em parcelas subdivididas, com quatro repetições, em que os fatores cultivar e as doses de $\mathrm{N}$ na emergência e em cobertura foram locados na parcela principal e subparcela, respectivamente. Cada parcela foi composta de 13 linhas de $3 \mathrm{~m}$ de comprimento, espaçadas em $0,18 \mathrm{~m}$, perfazendo $7,02 \mathrm{~m}^{2}$. A semeadura foi feita em 01/07/2009, na densidade de 300 sementes aptas $\mathrm{m}^{-2}$. A adubação, por ocasião da semeadura, foi de $66 \mathrm{~kg}$ $\mathrm{ha}^{-1}$ de $\mathrm{P}_{2} \mathrm{O}_{5}$ e $90 \mathrm{~kg} \mathrm{ha}^{-1}$ de $\mathrm{K}_{2} \mathrm{O}$. Os demais tratos culturais foram realizados conforme recomendação da pesquisa para o trigo (REUNIÃO..., 2011).

A reflectância do dossel foi avaliada pelo sensor óptico ativo Greenseeker. Esse sensor utiliza diodos de emissão de radiação nos comprimentos de onda do vermelho (650nm) e infravermelho próximo $(770 \mathrm{~nm})$ para determinação da reflectância, fornecendo o índice de vegetação por diferença normalizada (NDVI). O aparelho foi posicionado em uma altura de 1,0m acima do dossel. As leituras foram realizadas em toda extensão da parcela, com largura útil captada pelo sensor de $0,8 \mathrm{~m}$, nos estádios de desenvolvimento de quatro a cinco folhas expandidas, seis a sete folhas expandidas, emborrachamento e florescimento. O emborrachamento foi caracterizado quando a espiga encontrava-se envolta pela bainha da folha bandeira, enquanto que o florescimento foi definido quando, no mínimo, 50\% das plantas estavam florescidas e as anteras estavam visíveis. $\mathrm{O}$ rendimento de grãos, na umidade de $130 \mathrm{~g} \mathrm{~kg}^{-1}$, foi determinado pela colheita de uma área de $4,05 \mathrm{~m}^{2} \mathrm{em}$ cada parcela.

Para cada cultivar, modelou-se o rendimento de grãos em função do NDVI pelo ajuste de modelos linear $(\mathrm{y}=\mathrm{a}+\mathrm{bx})$ ou quadrático $\left(\mathrm{y}=\mathrm{a}+\mathrm{bx}+\mathrm{cx}^{2}\right)$. Os critérios utilizados para escolher o modelo mais adequado foram sua significância pelo teste $\mathrm{F}(\mathrm{P}=0,05)$, o maior coeficiente de determinação $\left(r^{2}\right)$ e a menor soma de quadrado dos resíduos 
(TOEBE et al., 2010). Para comparação dos modelos ajustados entre cultivares, foi calculado o intervalo de confiança dos coeficientes dos modelos (GOMES, 1990). Se os intervalos de confiança se sobrepõem, tem-se, no mínimo, 95\% de confiança de que os coeficientes não são significativamente diferentes.

\section{RESULTADOS E DISCUSSÃO}

Os valores do NDVI foram relacionados com o rendimento de grãos para cada cultivar estudada (Figura 1). As regressões ajustadas foram lineares para os estádios de quatro a cinco e seis a sete folhas expandidas (Figura 1A e 1B). Já no emborrachamento e florescimento, as regressões foram quadráticas (Figura 1C e 1D). Adicionalmente, ajustou-se um modelo único para as quatro cultivares testadas neste trabalho, englobando os valores das quatro cultivares.

Os coeficientes de determinação na primeira avaliação (Figura 1A) foram significativos para todas as cultivares e variaram entre $\mathrm{r}^{2}=0,61$ (cv. 'Quartzo') e r²=0,94 (cv. 'Marfim') (Figura 1A). Apesar de ser ainda cedo no ciclo da cultura para estimar o potencial produtivo em uma determinada área, o NDVI foi eficiente em quantificar diferenças entre o desenvolvimento das plantas frente às diferentes disponibilidades de $\mathrm{N}$, as quais resultaram em diferentes produtividades ao final do ciclo.

À medida que ocorreu o desenvolvimento da cultura, as correlações entre rendimento de grãos e NDVI foram aumentando, pois a superfície de fundo (solo e resíduos vegetais) passa a ter menor efeito sobre as leituras do NDVI (DALMOLIN et al., 2005) e a quantidade de biomassa da parte aérea passa a ser o fator preponderante que determina a magnitude desse índice (GROHS et al., 2007). No florescimento, o coeficiente de determinação, para o ajuste das quatro cultivares, foi de 0,94 (Figura 1D).

Os maiores valores de NDVI se relacionaram a maiores produtividades na colheita

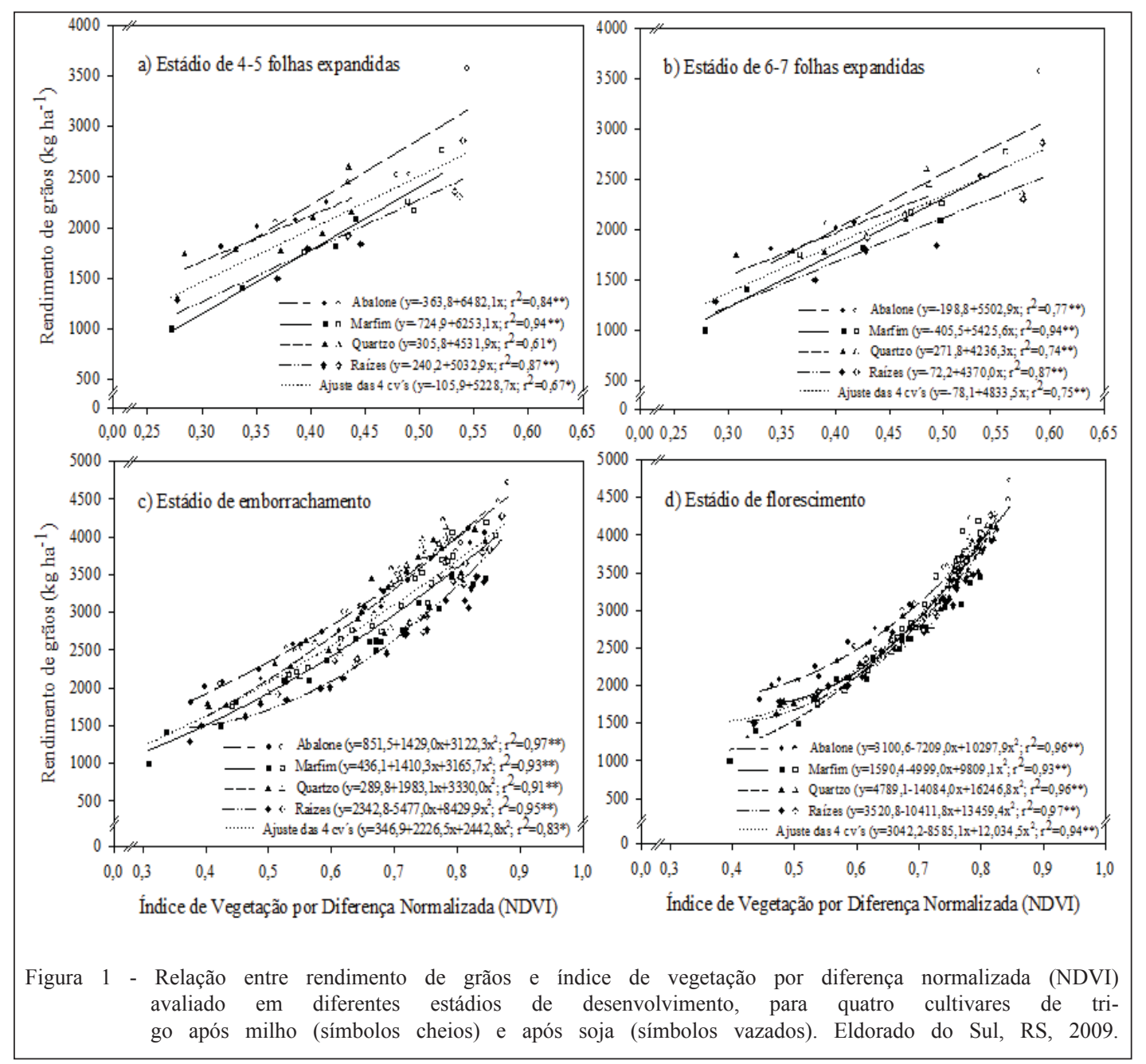

Ciência Rural, v.43, n.7, jul, 2013. 
(Figura 1). Essa relação também foi encontrada por POVH et al. (2008), que, trabalhando com adubação em taxa variável em trigo, encontraram valores de NDVI mais elevados em áreas que tinham recebido maior dose de $\mathrm{N}$ e apresentaram maior potencial produtivo. Nesse caso, o maior potencial produtivo foi proporcionado pela maior disponibilidade de $\mathrm{N}$ e maior acúmulo de biomassa e sobrevivência dos afilhos. GROHS et al. (2007), trabalhando com o sensor Greenseeker em cevada, encontraram alta correlação entre o NDVI avaliado no estádio de seis folhas expandidas, o número de colmos por área e a biomassa da parte aérea.

No estádio de seis folhas, que é o momento recomendado para aplicação de $\mathrm{N}$ em cobertura em cereais de estação fria (MUNDSTOCK \& BREDEMEIER, 2001; WAMSER \& MUNDSTOCK, 2007), é fundamental a estimativa do potencial produtivo da lavoura. Nesse estádio, as plantas ainda estão emitindo afilhos e iniciando a diferenciação das estruturas reprodutivas na inflorescência. Com a aplicação de doses condizentes com as reais necessidades da cultura, pode-se garantir maior sobrevivência desses afilhos, bem como maior número de grãos na espiga, definido pela diferenciação das espiguetas a partir desse período.

Uma vez quantificados os valores de NDVI no estádio de seis folhas, poder-se-ia realizar adubação com $\mathrm{N}$ em taxa variável, segundo o potencial produtivo estimado de cada local dentro da lavoura (MILANI et al., 2006). Assim, quanto melhor for o estado nutricional da cultura no momento de aplicação de $\mathrm{N}$ em cobertura, maior será o potencial produtivo e menor será a resposta à aplicação de nitrogênio (WELSH et al., 2003). A diferenciação de desenvolvimento da cultura dentro de uma área pelo NDVI poderia contemplar, por exemplo, três diferentes faixas de valores, que representariam diferentes potenciais de rendimento (baixo, médio e alto). A partir disso, seriam determinadas diferentes doses de $\mathrm{N}$ a serem aplicadas em cada faixa.

Essa forma de se manejar o nitrogênio leva à redução na aplicação desse nutriente em locais onde o potencial produtivo é alto, nos quais as plantas estão bem supridas e não haveria resposta a altas doses de $\mathrm{N}$ aplicadas, porém sem comprometer a produtividade. Segundo LAMOTHE (1994), quando elevadas quantidades de $\mathrm{N}$ forem absorvidas até o final do afilhamento, as plantas pouco responderão à adição de $\mathrm{N}$ em cobertura. Já em locais na lavoura onde os valores de NDVI são intermediários, seriam utilizadas doses maiores de $\mathrm{N}$, com o objetivo de maximizar o potencial produtivo desses locais.
Já a determinação do NDVI em estádios de desenvolvimento mais tardios (emborrachamento e florescimento) pode não ter mais funcionalidade sobre estratégias de manejo do $\mathrm{N}$ para aumento da produtividade, uma vez que o potencial de rendimento já está praticamente estabelecido (BREDEMEIER \& MUNDSTOCK, 2001). Contudo, vislumbra-se outros usos potenciais das leituras tardias de NDVI na cultura do trigo.

Com o auxílio de um sistema de posicionamento global, pode-se realizar leituras de NDVI de uma área, para posterior confecção de mapas da variabilidade espacial do potencial produtivo, conforme resultados mostrados na figura $1 \mathrm{C}$ e $1 \mathrm{D}$. JUNGES \& FONTANA (2011), trabalhando com NDVI obtido a partir de sensores orbitais (satélites), utilizaram os valores desse índice no florescimento para estimar produtividade de trigo no RS. Esses mapas também podem ser úteis na realização de amostragens de solo direcionadas aos locais onde se detectam diferenças de desenvolvimento da cultura e produtividade, para que se faça a investigação das causas e, se possível, se proceda à correção necessária para elevar o potencial produtivo em locais de baixo potencial, detectados por baixos valores de NDVI.

A utilização do NDVI para quantificação do potencial produtivo da cultura no florescimento pode também direcionar a aplicação de $\mathrm{N}$ em taxa variável para a melhoria da qualidade de grãos. Assim, para locais de menor potencial produtivo, detectado por menores valores de NDVI (Figura 1D), as quantidades de $\mathrm{N}$ a serem aplicadas seriam mais baixas do que para locais de alto potencial produtivo, pois, nesses locais, a elevada produtividade dilui o teor de N nos grãos (STONE \& SAVIN, 1999), reduzindo seu teor de proteína e sua qualidade para panificação. Assim, aplicação tardia de $\mathrm{N}$ no florescimento do trigo, baseada em leituras de NDVI, poderia aumentar o teor de proteína nos grãos e elevar sua qualidade (FUERTES-MENDIZÁBAL et al., 2010), agregando valor aos grãos no momento de sua comercialização. Entretanto, para se utilizar algoritmos na estimativa do potencial produtivo a partir de leituras do NDVI, é conveniente estabelecer um modelo padrão que possa ser empregado para um grupo de cultivares. Para tanto, calculou-se o intervalo de confiança dos coeficientes dos modelos ajustados para cada cultivar, considerando o modelo linear (Figura 1A e 1B) ou quadrático (Figura 1C e 1D).

Os intervalos de confiança são graficamente mostrados na figura 2 para os termos constante - "a" (Figura 2A), linear - "b" (Figura 2B) e quadrático - "c" (Figura 2C) dos modelos ajustados para 


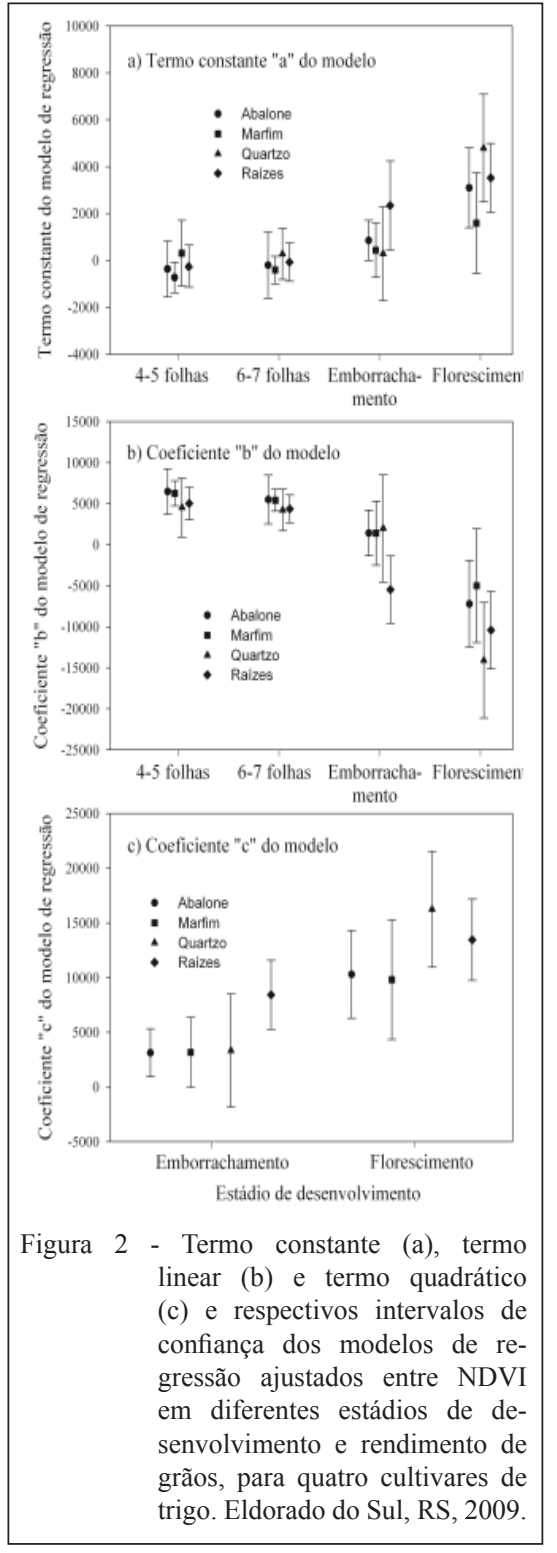

as diferentes cultivares para a relação entre NDVI e rendimento de grãos (Figura 1). De maneira geral, as sobreposições dos intervalos de confiança dos coeficientes em todos os estádios avaliados (Figura 2) mostram que o comportamento das cultivares de trigo foi similar para a relação entre NDVI e rendimento de grãos. Isso indica que seria possível adotar um modelo único para descrever a relação entre essas duas variáveis, sem a necessidade de se adotar modelos individuais para cada cultivar utilizada no presente trabalho. Considerando a aplicação prática, esse comportamento é desejável, uma vez que seria complexo o desenvolvimento de modelos específicos para cada cultivar, devido ao elevado número de cultivares de trigo recomendadas e utilizadas pelos produtores.

A aplicação de doses variáveis de fertilizantes nitrogenados em áreas espacialmente variáveis contribui para o aumento da eficiência de uso do N (RAUN et al., 2002). Estudos de campo indicam justificativas econômicas e ambientais para aplicação de $\mathrm{N}$ em taxa variável (LAMBERT et al., 2006; HONG et al., 2007). O N aplicado de maneira uniforme (aplicação em taxa fixa) ignora as diferenças espaciais e é um risco considerável ao meio ambiente, pela lixiviação de nitrato para águas superficiais e subterrâneas (SHANAHAN et al., 2008). Assim, o NDVI medido por sensor ativo pode ser empregado para estimar o potencial produtivo de diferentes áreas dentro de uma lavoura e, com essa informação, pode-se realizar a variação da dose de $\mathrm{N}$ aplicada.

Na tabela 1, são apresentadas as médias do rendimento de grãos dos tratamentos, considerando o cultivo de trigo após milho e após soja. Como $\mathrm{o}$ resultado do teste $\mathrm{F}$ não foi significativo para a interação entre os fatores "dose de N" e "cultivar", as médias são apresentadas em função do efeito principal de cada um desses dois fatores.

As maiores produtividades foram sempre observadas na condição de cultivo após soja, sendo que, para o mesmo tratamento com mesma dose de $\mathrm{N}$ na base e em cobertura, as produtividades registradas foram, na maioria das situações, cerca de $500 \mathrm{~kg} \mathrm{ha}^{-1}$ superiores às encontradas na condição após milho. Esses resultados já eram esperados, em função da maior disponibilidade de $\mathrm{N}$ para o trigo cultivado em sucessão à cultura da soja. Incrementos de produtividade entre 300 e $600 \mathrm{~kg} \mathrm{ha}^{-1}$ em trigo cultivado após soja, em comparação ao trigo cultivado após milho, também foram reportados por POLETTO (2004) e GROHS et al. (2009) no mesmo local de realização do experimento.

$\mathrm{Na}$ comparação entre tratamentos com as mesmas doses totais de $\mathrm{N}$ aplicadas, verificou-se que as maiores doses aplicadas em cobertura sempre foram mais importantes em elevar o rendimento de grãos do que quando as doses maiores foram aplicadas na base, independente se após milho ou após soja (Tabela 1). Por exemplo, na condição após milho, a aplicação de $20 \mathrm{~kg} \mathrm{ha}^{-1}$ de $\mathrm{N}$ na base e $60 \mathrm{~kg}$ ha ${ }^{-1}$ em cobertura produziu $3528 \mathrm{~kg} \mathrm{ha}^{-1}$ de grãos, enquanto que o tratamento com a aplicação de $60 \mathrm{~kg}$ $\mathrm{ha}^{-1}$ de $\mathrm{N}$ na base e $20 \mathrm{~kg} \mathrm{ha}^{-1} \mathrm{em}$ cobertura produziu $2536 \mathrm{~kg} \mathrm{ha}^{-1}$ de grãos. Isso demonstra a importância da adubação nitrogenada em cobertura no estádio de seis folhas expandidas do colmo principal. 
Tabela 1 - Rendimento de grãos de quatro cultivares de trigo, em função da dose de nitrogênio aplicada na emergência e em cobertura, no estádio de seis folhas completamente expandidas. Eldorado do Sul, RS, 2009.

\begin{tabular}{|c|c|c|c|c|c|c|}
\hline Emerg. & Cobert. & 'Abalone' & 'Marfim' & 'Quartzo' & 'Raízes’ & Média \\
\hline \multicolumn{2}{|c|}{ 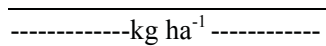 } & \multicolumn{5}{|c|}{ 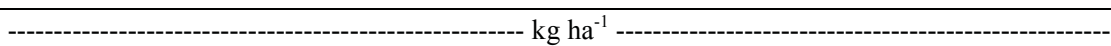 } \\
\hline 0 & 0 & 1807 & 998 & 1742 & 1287 & $1459 \mathrm{~m}^{1}$ \\
\hline 0 & 20 & 2115 & 1494 & 2324 & 1619 & 18881 \\
\hline 0 & 40 & 2743 & 2366 & 2623 & 2123 & $2464 \mathrm{gh}$ \\
\hline 0 & 60 & 3299 & 2624 & 3438 & 2778 & $3035 \mathrm{de}$ \\
\hline 0 & 80 & 3270 & 2617 & 3323 & 2708 & $2980 \mathrm{def}$ \\
\hline 20 & 0 & 2008 & 1406 & 1783 & 1497 & $1674 \mathrm{~m}$ \\
\hline 20 & 20 & 2575 & 2090 & 2490 & 1993 & $2287 \mathrm{hi}$ \\
\hline 20 & 40 & 3056 & 2497 & 3008 & 2714 & 2819 ef \\
\hline 20 & 60 & 3706 & 3048 & 3953 & 3403 & $3528 \mathrm{abc}$ \\
\hline 20 & 80 & 3909 & 3079 & 3548 & 3160 & $3424 \mathrm{c}$ \\
\hline 40 & 0 & 2073 & 1820 & 1764 & 1792 & 18621 \\
\hline 40 & 20 & 2573 & 2100 & 2282 & 1991 & $2237 \mathrm{i}$ \\
\hline 40 & 40 & 3073 & 2607 & 2913 & 2460 & $2763 \mathrm{f}$ \\
\hline 40 & 60 & 4104 & 3481 & 3727 & 3321 & $3658 \mathrm{ab}$ \\
\hline 40 & 80 & 3708 & 3126 & 3842 & 3157 & $3458 \mathrm{bc}$ \\
\hline 60 & 0 & 2247 & 2091 & 2098 & 1840 & $2069 \mathrm{ij}$ \\
\hline 60 & 20 & 2759 & 2654 & 2726 & 2005 & $2536 \mathrm{~g}$ \\
\hline 60 & 40 & 3428 & 2773 & 3514 & 2769 & $3121 \mathrm{~d}$ \\
\hline 60 & 60 & 4055 & 3451 & 3945 & 3472 & $3731 \mathrm{a}$ \\
\hline 60 & 80 & 3919 & 3377 & 4099 & 3066 & $3615 a b c$ \\
\hline \multicolumn{2}{|c|}{ Média } & $3021 \mathrm{a}$ & $2485 \mathrm{~b}$ & 2957 a & $2458 \mathrm{~b}$ & \\
\hline \multicolumn{2}{|c|}{ _-.-Dose de N-_- } & \multicolumn{5}{|c|}{ Após soja } \\
\hline Emerg. & Cobert. & 'Abalone' & 'Marfim' & 'Qigo-------- & 'Raízes' & Média \\
\hline \multicolumn{2}{|c|}{ - } & & & ---kg ha & & \\
\hline 0 & 0 & 2055 & 1754 & 1935 & 1918 & $1916 \mathrm{~h}$ \\
\hline 0 & 20 & 2484 & 2211 & 2533 & 2384 & $2403 \mathrm{~g}$ \\
\hline 0 & 40 & 3007 & 2826 & 3374 & 2931 & 3035 ef \\
\hline 0 & 60 & 3509 & 3527 & 3477 & 3411 & $3481 \mathrm{~d}$ \\
\hline 0 & 80 & 3526 & 3385 & 3620 & 3487 & $3505 \mathrm{~d}$ \\
\hline 20 & 0 & 2527 & 2169 & 2151 & 2356 & $2301 \mathrm{~g}$ \\
\hline 20 & 20 & 3089 & 2644 & 2979 & 2940 & $2913 \mathrm{f}$ \\
\hline 20 & 40 & 3594 & 3087 & 3453 & 3469 & $3401 \mathrm{~d}$ \\
\hline 20 & 60 & 3708 & 3699 & 3908 & 3794 & $3777 \mathrm{c}$ \\
\hline 20 & 80 & 3815 & 3658 & 4010 & 3654 & $3784 \mathrm{c}$ \\
\hline 40 & 0 & 2523 & 2263 & 2599 & 2305 & $2423 \mathrm{~g}$ \\
\hline 40 & 20 & 3004 & 2753 & 3150 & 2741 & $2912 \mathrm{f}$ \\
\hline 40 & 40 & 3586 & 3456 & 3752 & 3374 & $3542 \mathrm{~d}$ \\
\hline 40 & 60 & 3957 & 4055 & 3971 & 3820 & $3951 \mathrm{bc}$ \\
\hline 40 & 80 & 3921 & 3748 & 4130 & 3844 & $3911 \mathrm{c}$ \\
\hline 60 & 0 & 3572 & 2772 & 2445 & 2861 & $2913 \mathrm{f}$ \\
\hline 60 & 20 & 3790 & 3127 & 2792 & 2966 & $3169 \mathrm{e}$ \\
\hline 60 & 40 & 4222 & 3686 & 3791 & 3569 & $3817 \mathrm{c}$ \\
\hline 60 & 60 & 4726 & 4194 & 3930 & 4270 & $4280 \mathrm{a}$ \\
\hline 60 & 80 & 4467 & 4030 & 3879 & 4283 & $4165 \mathrm{ab}$ \\
\hline \multicolumn{2}{|c|}{ Média } & $3454 \mathrm{a}$ & $3152 \mathrm{a}$ & 3294 a & 3219 a & \\
\hline
\end{tabular}

${ }^{1}$ Médias seguidas pela mesma letra na coluna ou linha não diferem significativamente entre si pelo teste $t$, ao nível de $5 \%$ de probabilidade.

Ciência Rural, v.43, n.7, jul, 2013. 


\section{CONCLUSÃO}

As leituras do índice de vegetação por diferença normalizada (NDVI) ao longo do ciclo, utilizando sensor óptico ativo de reflectância, mostraram-se eficientes em identificar variações de produtividade na cultura do trigo, promovidas por variações na disponibilidade de nitrogênio. Considerando as cultivares utilizadas no presente trabalho, é possível adotar um modelo único para descrever a relação entre NDVI e rendimento de grãos, sem a necessidade de se adotar modelos individuais para cada cultivar isoladamente.

\section{REFERÊNCIAS}

BERGAMASCHI, H. et al. Clima da Estação Experimental da UFRGS e região de abrangência. Porto Alegre: UFRGS, 2003. $78 \mathrm{p}$

BREDEMEIER, C.; MUNDSTOCK, C.M. Estádios fenológicos do trigo para a adubação nitrogenada em cobertura. Revista Brasileira de Ciência do Solo, v.25, n.2, p.317-323, 2001. Disponível em: <http://sbcs.solos.ufv.br/solos/revistas/v25n2a08. pdf>. Acesso em: 10 mar. 2013.

DALMOLIN, R.S.D. et al. Relação entre os constituintes do solo e seu comportamento espectral. Ciência Rural, v.35, n.2, p.481489, 2005. Disponível em: <http://www.scielo.br/pdf/cr/v35n2/ a42v35n2.pdf>. Acesso em: 11 abr. 2012. doi: 10.1590/S010384782005000200042 .

DRURY, C.F. et al. The non-limiting and least limiting water ranges for soil nitrogen mineralization. Soil Science Society of America Journal, v.67, n.5, p.1388-1404, 2003. Disponível em: <https:// www.agronomy.org/publications/sssaj/articles/67/5/1388>. Acesso em: 20 mar. 2012. doi: 10.2136/sssaj2003.1388.

ERDLE, K. et al. Comparison of active and passive spectral sensors in discriminating biomass parameters and nitrogen status in wheat cultivars. Field Crops Research, v.124, p.74-84, 2011. Disponível em: <http://dx.doi.org/10.1016/j.fcr.2011.06.007>. Acesso em: 4 abr. 2012. doi: 10.1016/j.fcr.2011.06.007.

FENG, W. et al. Monitoring leaf nitrogen status with hyperspectral reflectance in wheat. European Journal of Agronomy, v.28, n.3, p.394-404, 2008. Disponível em: <http://dx.doi.org/10.1016/j. eja.2007.11.005>. Acesso em: 11 abr. 2012. doi: 10.1016/j. eja.2007.11.005

FUERTES-MENDIZÁBAL, $\mathrm{T}$. et al. Improving wheat breadmaking quality by splitting the $\mathrm{N}$ fertilizer rate. European Journal of Agronomy, v.33, n.1, p.52-61, 2010. Disponível em: $<\mathrm{http} / / /$ dx.doi.org/10.1016/j.eja.2010.03.001>. Acesso em: $11 \mathrm{abr}$ 2012. doi: 10.1016/j.eja.2010.03.001.

GOMES, F.P. Curso de estatística experimental. Piracicaba: Nobel, 1990. 468p.

GROHS, D.S. et al. Modelo para estimativa do potencial produtivo em trigo e cevada por meio do sensor Greenseeker. Engenharia Agrícola, v.29, n.1, p.101-112, 2009. Disponível em: <http://
dx.doi.org/10.1590/S0100-69162009000100011>. Acesso em: 11 abr. 2012. doi: 10.1590/S0100-69162009000100011.

GROHS, D.S. et al. Estimativa da biomassa e do potencial de rendimento de grãos em cevada através de medições de reflectância. In: REUNIÃO NACIONAL DE PESQUISA DE CEVADA, 26., 2007, Passo Fundo, RS. Anais... Passo Fundo: EMBRAPA, 2007. p.192-199.

HONG, S.D. et al. Comparison of ground-based remote sensors for evaluation of corn biomass affected by nitrogen stress. Communications in Soil Science and Plant Analysis, v.38, n.15, p.2209-2226, 2007. Disponível em: <http:// digitalcommons.unl.edu/ usdaarsfacpub/589/>. Acesso em: 04 abr. 2012. doi: 10.1080/00103620701549157.

JUNGES, A.H.; FONTANA, D.C. Modelo agrometeorologico-espectral de estimativa de rendimento de grãos de trigo no Rio Grande do Sul. Revista Ceres, v.58, p.695-700, 2011. Disponível em: <http://www.scielo. br/scielo.php?pid=S0034-737X2011000100002\&script $=$ sci arttext>. Acesso em: 11 abr. 2012. doi: 10.1590/S0034737X2011000100002.

LAMBERT, D.M. et al. Economic analysis of spatialtemporal patterns in corn and soybean response to nitrogen and phosphorus. Agronomy Journal, v.98, n.1, p.43-54, 2006. Disponível em: <https://www.agronomy.org/publications/aj/ abstracts/98/1/43>. Acesso em: 11 abr. 2012. doi: 10.2134/ agronj2005.0005.

LAMOTHE, A.G. Manejo del nitrógeno para aumentar productividad en trigo. Montevideo: INIA, 1994. 26p. (Série Técnica, 54).

MILANI, L. et al. Unidades de manejo a partir de dados de produtividade. Acta Scientiarum Agronomy, v.28, n.4, p.591598, 2006. Disponível em: <http://periodicos.uem.br/ojs/index. php/ActaSciAgron/article/view/937>. Acesso em: 04 abr. 2012. doi: $10.4025 /$ actasciagron.v28i4.937.

PEÑUELAS, J.; FILELLA, I. Visible and near-infrared reflectance techniques for diagnosing plant physiological status. Trends in Plant Science, v.3, n.4, p.151-156, 1998. Disponível em: <http://dx.doi.org/10.1016/S13601385(98)01213-8>. Acesso em: 04 abr. 2012. doi: 10.1016/ S1360-1385(98)01213-8.

POLETTO, N. Disponibilidade de nitrogênio no solo e sua relação com o manejo da adubação nitrogenada. 2004. 119f. Dissertação (Mestrado em Fitotecnia) - Programa de Pósgraduação em Fitotecnia, Universidade Federal do Rio Grande do Sul, Porto Alegre, RS.

POVH, F.P. et al. Comportamento do NDVI obtido por sensor ótico ativo em cereais. Pesquisa Agropecuária Brasileira, v.43, n.8, p.1075-1083, 2008. Disponível em: $<\mathrm{http} / / / \mathrm{dx}$.doi. org/10.1590/S0100-204X2008000800018>. Acesso em: 04 de abr. 2012. doi: 10.1590/S0100-204X2008000800018.

RAUN, W.R. et al. Improving nitrogen use efficiency in cereal grain production with optical sensing and variable rate application. Agronomy Journal, v.94, n.4, p.815-820, 2002. Disponível em: <http://nue.okstate.edu/index_publications/ ofit_2001.pdfs. Acesso em: 04 abr. 2012. doi: 10.2134/ agronj2002.8150. 
REUNIÃO DA COMISSÃO BRASILEIRA DE PESQUISA DE TRIGO E TRITICALE. Informações técnicas para trigo e triticale safra 2012. Dourados: Embrapa Agropecuária Oeste, 2011. 204p.

ROUSE, J.W. et al. Monitoring vegetation systems in the Great Plains with ERTS. In: THIRD EARTH RESOURCES TECHNOLOGY SATELLITE SYMPOSIUM, 1973, Washington, D.C. Volume 1: Technical presentations... Washington: NASA, 1973. p.309-317.

SALA, V.M.R. et al. Ocorrência e efeito de bactérias diazotróficas em genótipos de trigo. Revista Brasileira de Ciência do Solo v.29, n.3, p.345-352, 2005. Disponível em: <http://dx.doi. org/10.1590/S0100-06832005000300004>. Acesso em: 11 abr. 2012. doi: 10.1590/S0100-06832005000300004.

SCHMIDT, J.P. et al. Nitrogen recommendations for corn: an onthe-go sensor compared with current recommendation methods. Agronomy Journal, v.101, n.4, p.916-924, 2009. Disponível em: $<$ http://ddr.nal.usda.gov/bitstream/10113/32833/1/IND44234884. pdf>. Acesso em: 11 abr. 2012. doi: 10.2134/agronj2008.0231x.

SHANAHAN, J.F. et al. Responsive in-season nitrogen management for cereals. Computers and Electronics in Agriculture, v.61, n.1, p.51-62, 2008. Disponível em: <http:// dx.doi.org/10.1016/j.compag.2007.06.006>. Acesso em: 18 fev. 2012. doi: 10.1016/j.compag.2007.06.006.
STONE, P.J.; SAVIN, R. Grain quality and its physiological determinants. In: SATORRE, E.H.; SLAFER, G.A. Ecology and physiology of yield determination. Binghamton: Haworth, 1999. Cap.5, p.85-120.

STRECK, E.V. et al. Solos do Rio Grande do Sul. Porto Alegre: EMATER/RS, 2008. 222p.

TOEBE, M. et al. Estimativa da área foliar de Crambe abyssinica por discos foliares e por fotos digitais. Ciência Rural, v.40, n.2, p.475-478, 2010. Disponível em: <http://dx.doi.org/10.1590/ S0103-84782010000200036>. Acesso em: 04 abr. 2012. doi: $10.1590 / \mathrm{S} 0103-84782010000200036$.

WAMSER, A.F.; MUNDSTOCK, C.M. Adubação nitrogenada em estádios fenológicos em cevada, cultivar "MN 698". Ciência Rural, v.37, n.4, p.942-948, 2007. Disponível em: <http://dx.doi.org/10.1590/S010384782007000400004>. Acesso em: 18 fev. 2012. doi: 10.1590/S0103-84782007000400004.

WELSH, J.P. et al. Developing strategies for spatially variable nitrogen application in cereals. II: Wheat. Biosystems Engineering, v.84, n.4, p.495-511, 2003. Disponível em: $\quad<$ http://dx.doi.org/10.1016/S15375110(03)00003-5>. Acesso em: 11 abr. 2012. doi: 10.1016/ S1537-5110(03)00003-5. 